\title{
Behavioral Response of Two Subterranean Termites (Isoptera: Rhinotermitidae) to Vibrational Stimuli
}

\author{
Xing Ping Hu • Arthur G. Appel •
}

James F. A. Traniello

Published online: 6 July 2007

(C) Springer Science + Business Media, LLC 2007

At the request of Dr. J. F. A. Traniello, his co-authorship is removed from this paper (Vol. 16, No. 5, Sept. 2003, pp. 703-715). This action is due to the fact that Dr. Traniello provided only a collegial review of an early draft of the manuscript to the senior author and does not feel his contribution justifies authorship.

The online version of the original article can be found at http://dx.doi.org/10.1023/B: JOIR.0000007705.50488.57.

X. P. Hu $(\bowtie) \cdot$ A. G. Appel

Department of Entomology and Plant Pathology, Auburn University, Auburn, AL 36849, USA e-mail: huxingp@auburn.edu
A. G. Appel
e-mail: appelag@auburn.edu

J. F. A. Traniello

Biological Department, Boston University, 121 Bay State Road, Boston, MA 02215, USA 